\title{
Hypothermia prevention during surgery: comparison between thermal mattress and thermal blanket
}

\author{
PREVENÇÃO DA HIPOTERMIA NO TRANSOPERATÓRIO: COMPARAÇÃO ENTRE \\ MANTA E COLCHÃO TÉRMICOS
}

\section{PREVENCIÓN DE LA HIPOTERMIA DURANTE LA CIRUGÍA: COMPARACIÓN ENTRE LA MANTA Y EL COLCHÓN TÉRMICO}

\section{Ariane Marques Moysés ${ }^{1}$, Armando dos Santos Trettene ${ }^{2}$, Laís Helena Camacho Navarro², Jairo Aparecido Ayres ${ }^{4}$}

\begin{abstract}
This study aimed to compare the efficiency of the thermal blanket and thermal mattress in the prevention of hypothermia during surgery. Thirty-eight randomized patients were divided into two groups (G1 - thermal blanket and G2 - thermal mattress). The variables studied were: length of surgery, length of stay in the post-anesthetic care unit, period without using the device after thermal induction, transport time from the operating room to post-anesthetic care unit, intraoperative fluid infusion, surgery size, anesthetic technique, age, body mass index, esophageal, axillary and operating room temperature. In G2, length of surgery and starch infusion longer was higher (both $\mathrm{p}=0.03$ ), but no hypothermia occurred. During the surgical anesthetic procedure, the axillary temperature was higher at 120 minutes $(p=0.04)$, and esophageal temperature was higher at $120(p=0.002)$ and 180 minutes $(p=0.03)$ and at the end of the procedure $(p=0.002)$. The thermal mattress was more effective in preventing hypothermia during surgery.
\end{abstract}

\section{DESCRIPTORS}

Hypothermia

Perioperative period

Perioperative nursing

Postanesthesia nursing

\section{RESUMO}

O objetivo deste estudo foi comparar a eficiência da manta e colchão térmicos na prevenção da hipotermia no transoperatório. Participaram 38 pacientes randomizados em 2 grupos (G1 - manta térmica e G2 - colchão térmico). As variáveis estudadas foram: tempo cirúrgico, tempo de permanência na sala de recuperação pós-anestésica, tempo sem a utilização do dispositivo térmico após a indução anestésica, tempo de transporte entre a sala cirúrgica e a de recuperação, infusão defluido no intraoperatório, porte cirúrgico, técnica anestésica, idade, índice de massa corpórea, temperatura axilar, esofágica e da sala cirúrgica. No G2, o tempo cirúrgico e a infusão de amido foram maiores (ambos $p=0,03$ ), porém, não ocorreu hipotermia. Durante o procedimento anestésico cirúrgico, a temperatura axilar foi maior aos 120 minutos $(p=0,04)$ e a temperatura esofágica foi maior aos $120(p=0,002)$, aos 180 minutos $(p=0,03)$ e ao final da cirurgia $(p=0,002)$. 0 colchão térmico mostrou-se mais eficaz na prevenção da hipotermia no transoperatório.

\section{RESUMEN}

El objetivo de este estudio fue comparar la eficacia de la manta y el colchón térmico en la prevención de la hipotermia durante el trans-operatorio. Participaron 38 pacientes asignados al azar en dos grupos (G1 - manta térmica y G2 - colchón térmico). Las variables estudiadas fueron: tiempo quirúrgico, tiempo de permanencia en la sala de recuperación post-anestésica (URPA), tiempo sin utilizar el dispositivo térmico después de la inducción anestésica, tiempo de transporte entre el quirófano y la URPA, infusión de fluidos durante el intra-operatorio, tamaño de la cirugía, técnica anestésica, edad, índice de masa corporal, temperatura axilar, esofágica y de la sala quirúrgica. En el G2, el tiempo quirúrgico y la infusión de almidón fueron mayores (ambos $p=0,03$ ), pero no se produjo la hipotermia. Durante la anestesia quirúrgica, la temperatura axilar fue mayor a los 120 minutos $(p=0,04)$, y la temperatura esofágica fue mayor a los $120(\mathrm{p}=$ $0,002)$ y 180 minutos $(p=0,03)$ y al final de la cirugía $(p=0,002)$. El colchón térmico fue más eficaz en la prevención de la hipotermia durante la cirugía.

\author{
DESCRITORES \\ Hipotermia \\ Período perioperatório \\ Enfermagem perioperatória \\ Enfermagem em pós-anestésico
}

\section{DESCRIPTORES \\ Hipotermia \\ Periodo perioperatorio \\ Enfermería perioperatoria \\ Enfermería postanestésica}




\section{INTRODUCTION}

Hypothermia is defined as a core body temperature lower than $36^{\circ} \mathrm{C}$ and is one of the most common complications during surgical anesthesia, incident that affects approximately $70 \%$ of patients ${ }^{(1)}$. It occurs due to the abolition of behavioral responses after anesthetic induction, increased patient exposure to the environment (refrigerated rooms), central inhibition of thermoregulation induced by anesthetics, internal interior redistribution of heat, thoracic or abdominal cavity and infusion of cold solutions ${ }^{(2)}$.

Among the implications related to the occurrence of unintended perioperative hypothermia include increased risk of bleeding, tachycardia, morbid cardiac events, surgical site infection and prolonged hospital stay ${ }^{(3)}$. Other possible complications include decreased level of consciousness, increased pharmacological half-life of anesthetics, decreased urine output, tremor, exacerbation of postoperative pain, increased risk of deep venous thrombosis by causing venous stasis and high demand for oxygen ${ }^{(4-6)}$.

Hypothermia is more common in longer surgeries because the steepest drop in temperature occurs 40 to 60 minutes after the start of anesthesia. Thus, it is essential to measure the core temperature in all surgical procedures, but especially those with more than 30 minutes $^{(3)}$.

Human beings need their internal temperature to be constant, because that is how we preserve our necessary metabolic functions for our survival. Maintaining normothermia is a challenge for the staff, especially nursing, since it is our responsibility to install and monitor the devices in order to prevent hypothermia. The nurse, through evidence-based practices, should formalize protocols, implement and evaluate nursing interventions to prevent hypothermia.

The motivation for conducting this study arose from questions present in clinical practice because we quite frequently found patients having hypothermia during surgery, a period that includes the immediate and mediate intra- and post-operatory. In this study, we focused on the intraoperative period, addressing only the immediate postoperative period.

In the post-anesthesia care unit (PACU), there are countless complaints about the uneasiness caused, for example, by the tremors. Many are the hypotheses for the occurrence of intraoperative hypothermia, including the unavailability of active thermal devices, cooling the operating room and the lack of more effective methods among those available for its prevention. Such devices may be classified into passive (blankets, burrows, strapping members with orthopedic bandage and cotton crepe, aluminum blankets, etc.) and active (air, water and radiation heating systems, carbon fiber blankets, among others).

Studies comparing methods of heating are common, but in the databases searched, no studies were found comparing the thermal blanket and thermal mattress, which justifies the performance of this research. The choice of these two devices lies in the fact that they are more technologically advanced, and cover larger body surface, properties that result in greater efficacy.

Given the above, the question guiding this study was: - Which is the best device, the thermal blanket or the thermal mattress, used to prevent hypothermia during surgery?

We hope this study may contribute to the optimization of patient care during surgery, related to the prevention of hypothermia, also emphasizing the role of the nurse and their staff for this purpose. We still hope that the knowledge obtained could raise and support new research, since in the available literature no study that compared the effectiveness of the two active heating methods used in this study was found.

The aim of the study was to compare the efficiency of the devices thermal blanket and thermal mattress in the prevention of hypothermia during surgery. As specific objectives, we sought to relate the incidence of hypothermia during surgery using the devices thermal blanket and thermal mattress and correlate them to the following parameters: length of surgery, length of stay in the post-anesthesia recovery unit (PACU), time without the use of thermal device after anesthetic induction, transportation time between the surgical anesthetic technique room and PACU, intraoperative fluid infusion, surgical and operating room temperature. We also sought to relate the occurrence of hypothermia during surgery using a thermal blanket and thermal mattress to age and body mass index (BMI).

\section{METHOD}

This is prospective, cross-sectional, randomized, double-blind study with a quantitative design, developed at the Surgical Center of the Clinics Hospital of the Faculty of Medicine of Botucatu (FMB) - UNESP, in the period from January to October 2011.

The Clinics Hospital of the FMB - UNESP has 467 beds for various clinical and surgical specialties. Surgical Center Unity has 11 rooms, 9 for elective surgeries and 2 for emergency and urgency care. The PACU has 8 beds. The PACU nursing team consists of 1 nurse, 3 nursing technicians and 3 nursing assistants per shift. The daily average of surgery is about 35, that is, 778 surgeries per month.

The study population consisted of patients undergoing open gastrointestinal surgery, sizes II, III and IV, according to the duration, therefore, size II lasts for about two to four hours, size III, four to six hours, and size IV, with more than six hours of surgery. Annually, approximately 386 open gastrointestinal surgeries, lasting at least two hours are performed.

Considering the sample size calculation, the sample was composed of 38 patients. Inclusion criteria were patients 
aged 18 to 66 years, surgical positioning in the supine position and performing the anesthetic recovery in the PACU.

Data collection began after the approval of the research project by the Ethics Research Committee Involving Human Subjects of the institution, under the protocol number 3731/2010. The subjects formalized their participation with the signing of the Consent Form.

In order to carry out this study, patients were randomized into two groups (G1 and G2) consisting of 19 patients. Randomization was performed immediately prior to admission in the operating room, by drawing an envelope containing the statement about which group the patient would be inserted.

G1 used the thermal blanket, which was positioned in the lower limbs after indwelling catheter (IC). Then, the blanket was connected to the air hose, which had the $38^{\circ} \mathrm{C}$ temperature.

G2 used the thermal mattress that was placed on the surgical table and filled with a device called the main unit, consisting of two air tubes and hand control. The programmed temperature was initially $37^{\circ} \mathrm{C}$, which was checked on the hand control display. After this observation, patients were placed in the horizontal supine position, in direct contact with the mattress. At the end of the IC, the mattress temperature was set at $38^{\circ} \mathrm{C}$.

After accommodating the patient on the surgical table, the monitoring began (cardioscopy, axillary temperature, pulse oximetry and noninvasive blood pressure). After that, the temperature of the operating room was verified. Both axillary temperature as the operating room temperature were recorded in the instrument of data collection. At the end of anesthetic induction, the installation of an esophageal thermometer occurred. The axillary, esophageal and surgery room temperatures were measured again and recorded in the instrument of data collection. Measurements of temperature were performed by nursing technicians who were already active in the sector, after training conducted by one of the researchers. All data collection in relation to the environment or the patient temperature, either in the operating room, or in the PACU were conducted by an evaluator who did not know which group the patient belonged to.

The time period in which the patient was exposed to environment temperature, ie until the end of the IC, it has been addressed in order to influence hypothermia, since the patient had no heating devices at the moment. The axillary, esophageal and operating room temperatures were measured every 30 minutes until the end of the surgical procedure.

During transference of the patient from the operating room to the PACU, the devices were disabled and that period was timed until the devices were reactivated. In the PACU, the $\mathrm{G1}$, in which the thermal blanket was positioned in the lower limbs, was replaced by another one, besides the lower limbs, the blanket would also cover the abdomen and thorax. In the G2, the thermal mattress was maintained. Thereafter, the axillary temperature was measured every 15 minutes until it reached $36^{\circ} \mathrm{C}$.

In both groups, esophageal and axillary temperatures were measured by means of a monitor that continuously measured the temperature. The room temperature (operating room) was also measured by a temperature monitor that was triggered at pre-specified moments in the study.

For data collection, we used an instrument designed specifically for this purpose, consisting of 3 items: characterization of patient, factors related to the surgical procedure and aspects related to post-anesthesia recovery.

Regarding the characterization of the patient, we sought to identify the age and BMI. As to factors related to the surgical procedure, the type and size of surgery was assessed, the thermal device used, type of anesthesia, the time without thermal device after anesthetic induction at the beginning and end of the surgery, the temperature of the operating room, esophageal and axillary temperatures, and the amount of infused solutions. Regarding aspects of post-anesthetic recovery, we sought to identify the transport time between the operating room and recovery room (no heating devices were on), the time of admission and the measurement of axillary temperature.

The dependent variables were age, BMI, fluid infusion during surgery, duration of surgery, time without the use of the thermal device, length of stay in the PACU, transport time and temperature of the operating room. The independent variables were the type of general anesthesia and surgery size.

The t-Student test was used to analyze the significance between independent samples, considering as statistically significant $p$-value $<0.05$ (5\%). Statistical evaluation of data was performed by the evaluator who was not informed of the group of each patient belonged.

\section{RESULTS}

Thirty eight patients participated in the study with a mean age of 57.5 years $( \pm 13.05)$. In relation to gender, a predominance of males was observed $(55 \%, n=21)$.

Relating the groups to surgical time, length of stay of patients in the PACU, time without using the thermal device after anesthetic induction and transport time between the operating room and PACU, it became clear that the G1 surgical time was shorter $(p=0.03)$ and time without thermal device was greater $(p=0.03)$. We also observed a tendency for the length of stay in the PACU to be longer in $\mathrm{G1}$ ( $p=0.06)$, as shown in Table 1.
Hypothermia prevention during surgery: comparison between thermal mattress and thermal blanket Moysés AM, Trettene AS, Navarro LHC, Ayres JA 
Regarding axillary, esophageal and the operating room temperatures, it was found that axillary temperature at 120 minutes after the start of anesthesia was higher in G2 $(p=0.04)$ and esophageal temperature was greater in $G 2$ at 120,180 minutes and at the end of surgical anesthesia procedure (Table 2).
When investigated the surgical duration and anesthetic technique used, it was observed that in $\mathrm{G} 2$ there was greater number of size III surgeries $(p=0.02)$ (Table 3$)$.

Table 4 shows the distribution of patients according to their need for fluid replacement during surgery. It is observed that in $G 2$ the infusion of starch was higher $(p=0.03)$.

Table 1 - Distribution of participants with regard to surgical time, length of time of patient in the post-anesthetic recovery room, time without using the thermal device after anesthetic induction and transport time between the operating room and PACU - Botucatu, SP 2011

\begin{tabular}{ccccc}
\hline & Surgery time & PACU time & Time without the use of the thermal device & Time of transportation until PACU \\
\hline G1 (n=19) & $214.6 \pm 91.1^{*}$ & $115.4 \pm 47.3$ & $9.8 \pm 5.2^{*}$ & $8.1 \pm 3.7$ \\
G2 $(\mathbf{n}=\mathbf{1 9})$ & $291.6 \pm 115.2$ & $82.5 \pm 53.1$ & $7.0 \pm 2.0$ & $8.9 \pm 5.3$ \\
$\mathbf{P}$ & $0.03^{*}$ & 0.06 & $0.03^{*}$ & 0.55 \\
\hline
\end{tabular}

t-Student test

*Significant association $(p \leq 0,05)$

Table 2 - Distribution of patients with axillary temperature and esophageal temperature of the operating room, at different moments Botucatu, SP 2011.

\begin{tabular}{|c|c|c|c|c|c|c|c|c|c|}
\hline & \multicolumn{3}{|c|}{ Operating room temperature } & \multicolumn{3}{|c|}{ Axillary temperature } & \multicolumn{3}{|c|}{ Esophageal temperature } \\
\hline & G1 & G2 & $\mathbf{P}$ & G1 & G2 & p & G1 & G2 & $\mathbf{P}$ \\
\hline Admission & $22.7 \pm 2.1$ & $23.3 \pm 1.5$ & 0.25 & $35.5 \pm 0.7$ & $35.4 \pm 0.8$ & 0.83 & - & - & - \\
\hline T 0 & $22.5 \pm 1.7$ & $23.0 \pm 1.5$ & 0.37 & $35.5 \pm 0.7$ & $35.3 \pm 0.8$ & 0.37 & $36.1 \pm 0.6$ & $35.9 \pm 0.8$ & 0.49 \\
\hline T 30min & $22.5 \pm 1.5$ & $22.9 \pm 1.4$ & 0.37 & $35.2 \pm 0.7$ & $35.2 \pm 0.9$ & 0.93 & $35.9 \pm 0.7$ & $36.3 \pm 0.6$ & 0.14 \\
\hline $\mathrm{T}$ 60min & $21.9 \pm 1.5$ & $22.1 \pm 1.3$ & 0.64 & $35.2 \pm 0.7$ & $35.1 \pm 1.4$ & 0.8 & $35.7 \pm 0.7$ & $36.0 \pm 1.0$ & 0.19 \\
\hline T 120min & $21.3 \pm 1.5$ & $21.2 \pm 1.3$ & 0.81 & $34.8 \pm 0.8$ & $35.3 \pm 0.9^{*}$ & $0.04 *$ & $35.4 \pm 0.6$ & $36.1 \pm 0.7^{*}$ & $0.002 *$ \\
\hline final T & $21.5 \pm 1.5$ & $21.5 \pm 1.3$ & 0.89 & $34.8 \pm 0.7$ & $35.2 \pm 0.9$ & 0.12 & $35.2 \pm 0.9$ & $36.1 \pm 0.7^{*}$ & $0.002 *$ \\
\hline
\end{tabular}

t-Student test

*significant association $(p \leq 0,05)$

in which $\mathrm{TO}=$ temperature after anesthetic induction

Table 3 - Distribution of patients according to the surgical size and anesthetic technique used - Botucatu, SP 2011.

\begin{tabular}{|c|c|c|c|c|c|}
\hline & \multicolumn{3}{|c|}{ Surgical size } & \multicolumn{2}{|c|}{ Anesthetic technique } \\
\hline & II & III & IV & GIRC & GEV \\
\hline G1 $(n=19)$ & $68 \%(13 / 19)$ & $21 \%(4 / 19)$ & $11 \%(2 / 19)$ & $63 \%(12 / 19)$ & $37 \%(7 / 19)$ \\
\hline$G 2(n=19)$ & & $\mathrm{p}=0.02 *$ & & \multicolumn{2}{|c|}{$\mathrm{p}=0.74$} \\
\hline
\end{tabular}

t-Student test

*significant association ( $p \leq 0,05)$

$\mathrm{GICB}=$ General inhalation with controlled breathing; IVG= Intravenous general

Table 4 - Distribution of participants according to the need of fluid replacement during surgery - Botucatu, SP 2011.

\begin{tabular}{cccc}
\hline & Crystalloid & Starch & RC \\
\hline G1 $(\mathbf{n = 1 9 )}$ & $2878.9 \pm 1376.7$ & $541.7 \pm 144.3(13 / 19)$ & $412.3 \pm 157.0(8 / 19)$ \\
G2 $(\mathbf{n = 1 9 )}$ & $3023.7 \pm 1160.5$ & $730.8 \pm 259.4(13 / 19)^{*}$ & $598.9 \pm 398.3(9 / 19)$ \\
P & 0.73 & $0.03^{*}$ & 0.23 \\
\hline
\end{tabular}

t-Student test

*significant association $(p \leq 0,05)$

Legend: where $\mathrm{RC}=$ red blood cells; $\mathrm{PFC}=$ plasma

\section{DISCUSSION}

There are various studies comparing methods of heating, nevertheless, there have been divergences between them. Studies suggest that passive heating methods are not effective in maintaining the temperature of patients in the perioperative period.
One study compared the use of common blankets in elderly patients undergoing elective surgery. Three groups participated in the study, 2 were experimental (EG1 and EG2) and 1 was the control group (CG). In EG1 patients had their whole body surface covered by a blanket, except the surgical site. In GE2 the heating of the dorsal region of the patient occurred with a blanket and 
GC did not use any devices. No significant temperature differences were observed between the groups, demonstrating the ineffectiveness of the blanket to maintain normothermia during surgery ${ }^{(7)}$.

Recent meta-analysis with the objective to identify the effectiveness of different devices of heating systems for temperature control in patients undergoing elective surgeries revealed that passive heating methods were less effective ${ }^{(8)}$.

Although there is evidence for the use of active heating methods for efficacy study with the objective of identifying the measures adopted in the operating room to prevent hypothermia during the intraoperative period, it pointed to the predominance of passive heating methods, perhaps due to the lack of more effective methods or difficulty acquiring devices because of the $\operatorname{cost}^{(9)}$.

In relation to active heating methods, all are efficient, although some seem to be more efficient than others, as demonstrated by the present study, in which the use of thermal mattress was more efficient than the thermal blanket to prevent hypothermia in patients undergoing open abdominal surgery, corroborating the findings of the literature.

An investigation compared the conductive heating methods (mattress of circulating water) alone and associated with convection (mattress of circulating water and blanket of heated air) and concluded that, although the combination of heating methods have delayed intraoperative hypothermia installation and decreased its intensity, it did not reduce the incidence of complaints of cold and tremors in the postoperative period ${ }^{(10)}$.

Another study compared a system of conductive heating of hot water circulation around a single extremity (vital HEAT) with the thermal blanket system (Bair Hugger) in patients undergoing orthopedic surgery and concluded that the thermal blanket was more efficient in the maintenance of intraoperative normothermia.

Another study compared the use of air blanket to conductive blanket, concluding that both devices had similar efficacy in maintaining normothermia, still emphasizing the feasibility of blanket resistance against the $\operatorname{cost}^{(12)}$.

Another study compared two systems of convection heating (Bair Hugger and WairAir) in patients undergoing orthopedic and abdominal major surgery, concluding that both heating systems were effective in maintaining perioperative normothermia ${ }^{(13)}$.

Despite many studies on the topic in the literature, in the data bases searched, no studies that compared the effectiveness of the thermal blanket and thermal mattress in preventing hypothermia in the intra and post-operatory were found, emphasizing the relevance of this study.
Patients undergoing various surgeries in the abdominal cavity are particularly susceptible to hypothermia due to exposure, usually prolonged, of large visceral ambient to operating room temperature, when the conventional approach is used ${ }^{(14)}$. Thus, open gastrointestinal surgeries contribute to hypothermia, both in the intra and postoperative periods, mainly due to extensive exposure of the viscera to the environment and a greater need for volume infusion of intravenous fluids during surgery ${ }^{(10,15)}$.

Relating groups to surgical time and intraoperative hypothermia occurrence, it was found that the G2 had longer surgical time, however, this was not reflected in the incidence of hypothermia.

Hypothermia is more frequent in long surgeries because the steepest drop in temperature occurs within the first 40 to 60 minutes after induction of anesthesia ${ }^{(16)}$. We associate this result to the heating method, in which $\mathrm{G} 2$ covered the entire dorsal body, while G1 covered only the lower limbs. Active heating methods are effective in preventing hypothermia, but are directly related to body length in contact with the device ${ }^{(1,3-4)}$.

In the present study, the mean temperature of the operating room during the intraoperatory remained between 20.7 and $23.3^{\circ} \mathrm{C}$. These results are in accordance with the standards of the American Society of Perianesthesia Nurses (ASPAN), which guides the maintenance of ambient operating room temperature between 20 and $24^{\circ} \mathrm{C}^{(17)}$. The operating room temperature was lower than the operative values referred above contributes to the occurrence of perioperative hypothermia ${ }^{(15)}$.

The increased length of stay of patients in the PA$\mathrm{CU}$ is associated with complications from intraoperative hypothermia, reflecting increased costs, need for transfusions, administration of medications and ordering additional laboratory tests ${ }^{(2)}$. Patients heated by active heating air systems remain shorter time in PACU, as well as minimizing costs associated with postoperative hypothermia ${ }^{(18)}$.

In a study using a thermal blanket in the intraoperative period in patients undergoing radical prostatectomy, the authors related its use to the significantly decreased length of stay in the PACU ${ }^{(19)}$. In the present investigation, however, when considering the length of stay in the PACU and hypothermia occurrence, no significant difference between the groups was observed.

Considering that the patients were discharged from the heated operating room, it was expected that the length of stay in the PACU was lower in G2, since there was significant difference between the groups when comparing the occurrence of intraoperative hypothermia. This result was associated with the method used for the PACU discharge, the Aldrete Kroulik Index, which evaluates the clinical signs other than temperature, such 
as muscle activity, respiration, circulation, consciousness and $\mathrm{O} 2$ saturation.

When assessing the time to trigger the heating system in $\mathrm{G} 1$ and $\mathrm{G} 2$, it became clear that the $\mathrm{G} 2$ time was shorter. In G1, after performing the IC, the positioning of blanket in the lower limbs and the connection of the hose. After this moment, the heating was initiated. In the $\mathrm{G} 2$, the mattress had been placed under the patient, that is, after the IC, it was only necessary to adjust the temperature, justifying the results. Heating methods must be installed early in the preoperative period and maintained until the moment the surgeon starts the preparation of the skin ${ }^{(14)}$. This result reflects the benefits of thermal mattress, since besides a coverage of a larger body structure, it also minimizes installation time compared to the thermal blanket, contributing to the prevention of hypothermia.

Comparing the infusion of intravenous solutions and intraoperative hypothermia, it was observed that the G2 infusion of starch was higher due to prolonged surgical time and the surgical size, however, hypothermia was not observed. Although the heating fluid contributes to the prevention of hypothermia(15,20), only the crystalloid (saline solution, Ringer lactate and glucose solution) is heated, that is, the starch was administered at room temperature. Therefore, the result found may be associated with the use of thermal mattress.

In intra-cavitary surgery, in which the surgical field restricts the heated area, limitation may compromise the maintenance of normothermia, in these cases, thermal mattress are indicated ${ }^{(10)}$. The size and therefore, the surgical time, and exposure of the viscera to room temperature (higher in G2) are referred to as variables that contribute to the occurrence of hypothermia.

Several authors ${ }^{(1,3-4)}$ associate the efficiency of the active heating method to body covered extension, that is, the amount of heat transferred to the patient is the main determinant in preventing the onset of perioperative hypothermia. In this context, it is evident the benefit of thermal mattress in relation to the thermal blanket.

In stratifying patients according to the axillary and esophageal temperatures, there was significant difference in $\mathrm{G} 2$ axillary temperature at 120 minutes. Regarding esophageal temperature, we noticed a statistical significance at 120 and 180 minutes and at the end of the procedure. This result corroborates the benefits of verification of core temperature, indicated in the literature as the most effective ${ }^{(10)}$. Esophageal temperature in $\mathrm{G} 1$ showed a decrease during the surgical procedure, while in G2, it remained almost constant, demonstrating the effectiveness of thermal mattress in normothermia.

When comparing the mean axillary temperatures of patients in the PACU, no significant difference was found, but in both groups, patients were hypothermic upon admission into the room, keeping this situation up to 60 minutes after admission. This result can be attributed to the physical distance between the operating room and PACU, and the fact that during transference all heating devices were off, contributing to hypothermia occurrence.

Associating the influence of surgical size and hypothermia occurrence, it was observed that in $\mathrm{G} 2$, patients showed normothermia, which goes against logical reasoning, that is, the larger the size, the higher the surgical time, and consequently, the greater the possibility of hypothermia. This result could be related to the fact that thermal mattresses cover larger body surface, which, regardless of the surgical time, promotes normothermia. In intra-cavitary surgeries, in which the surgical field restricts the heated area, this characteristic of thermal mattress helps maintain the temperature in medium and large abdominal surgeries ${ }^{(10)}$.

Given the above, we emphasize the importance of nurses in perioperative temperature monitoring of patients. Nursing interventions include monitoring of body and core temperature during the pre, intra and post-operatory and the installation of methods for active or passive heating during the intraoperative period ${ }^{(21)}$.

Due to early bath in the morning, skin preparation, lack of clothing, the vasodilatory effects of pre-anesthetic medications, among others, many patients come to the operating room hypothermic ${ }^{(22)}$. Therefore, we emphasize the need to implement preoperative nursing interventions, including the use of blankets and air heating systems.

The assessment conducted by the nursing staff in the preoperative period is essential to facilitate the identification of patients at risk of developing hypothermia. Simple precautionary measures initiated by the nursing staff, can greatly reduce heat loss, minimize the risk of associated complications and improve patient recovery in short and long term ${ }^{(23)}$. Nurses are responsible for planning and implementing effective interventions for the prevention or treatment of hypothermia and consequently the reduction of the complications associated with this event ${ }^{(8)}$.

We believe that this study contributes to the clinical practice to identify a more effective heating method. However, other studies comparing active heating methods are necessary and also involving association of other variables to the use of these devices, such as implications of nursing workload, costs, the need for equipment maintenance and staff training are needed.

\section{CONCLUSION}

It was noted in this study that the amount of heat transferred to the patient is the main determinant in preventing the onset of perioperative hypothermia. In this context, the thermal mattress was more effective than the thermal blanket to prevent hypothermia in the intra and postoperative period. 


\section{REFERENCES}

1. Bernardis RCG, Silva MP, Gozzani JL, Pagnocca ML, Mathias LAST. Uso da manta térmica na prevenção de hipotermia intraoperatória. Rev Assoc Med Bras. 2009;55(4):421-6.

2. Poveda VB, Galvão CM, Santos CB. Factors associated to the development of hypothermia in the intraoperative period. Rev Latino Am Enferm. 2009;17(2):228-33.

3. Li Bassi G. Perioperative hypothermia: the delicate balance between heat gain and heat loss. Minerva Anestesiol. 2008;74(12):683-5.

4. Moretti B, Larocca AMV, Napoli C, Martinelli D, Paolillo L, Cassano $M$, et al. Active warming systems to maintain perioperative normothermia in hip replacement surgery: a therapeutic aid or a vector of infection? J Hosp Infect. 2009;73(1):58-63.

5. Brandt S, Oguz R, Huttner H, Waglechener G, Chiari A, Greif $R$, Kurz A, Kimberger O. Resistive-polymer versus forced air warming: comparable efficacy in orthopedic patients. Anesth Analg. 2010;110(3):834-8.

6. Woolnough MJ, Hemingway $C$, Allam J, Cox M, Yentis SM. Warming of patients during caesarean section: a telephone survey. Anaesthesia. 2009;64(1):50-3.

7. Tramontini CC, Graziano KU. Hypothermia control in elderly surgical patients in the intraoperative period: evaluation of two nursing interventions. Rev Latino Am Enferm. 2007;15(4):626-31.

8. Poveda VB, Galvão MC. Hypothermia in the intraoperative period: can it be avoided? Rev Esc Enferm USP [Internet]. 2011[cited 2012 Dec 11];45(2):411-7. Available from: http:// www.scielo.br/pdf/reeusp/v45n2/en_v45n2a15.pdf

9. Poveda VB, Martinez EZ, Galvão CM. Active cutaneous warming systems to prevent intraoperative hypothermia: a systematic review. Rev Latino Am Enferm [Internet]. 2012 [cited 2013 Dec 11];20(1):183-91. Available from: www.scielo.br/ pdf/rlae/v20n1/pt_24.pdf

10. Pagnocca ML, Tai EJ, Dwan JL. Controle de temperatura em intervenção cirúrgica abdominal convencional: comparação entre os métodos de aquecimento por condução e condução associada à convecção. Rev Bras Anestesiol. 2009;59(1):55-66.

11. Trentman TL, Hentz JG, Simula DV. Randomized non-inferiority trial of the vitalHEATTM Temperature Management System vs the Bair Hugger ${ }^{\circledR}$ warmer during total knee arthroplasty. J Can Anesth. 2009;56(1):914-20.
12. Perl T, Flother L, Weyland W, Quintel M, Brauer A. Comparison of forced-air warming and resistive heating. Minerva Anestesiol. 2008;74(12):687-90.

13. Wagner K, Swanson E, Raymond CJ, Smith CE. Comparison of two connective warming sysrems during major abdominal and orthopedic surgery. Can J Anesth. 2008;55(6):258-63.

14. Galvão CM, Marck PB, Sawada NO, Clark AM. A systematic review of the effectiveness of cutaneous warming systems to prevent hypothermia. J Clin Nurs. 2009;18(5):627-36.

15. Paulikas C. A Prevention of unplanned perioperative hypothermia. AORN J. 2008;88(3):358-64.

16. Brauer A, Bovenschulte $H$, Thorsten P, Zink W, Murray MJ, Quintel M. What determines the efficacy of Forced-Air Warming systems? A manikin evaluation with upper body blankets. Anesth Analg. 2009;108(1):192-8.

17. Berry D, Wick C, Magons P. A clinical evaluation of the cost and time effectiveness of the ASPAN hypothermia guideline. J Perianesth Nurs. 2008;23(1):24-35.

18. Fallis WM, Hamelin K, Symonds J, Wang X. Maternal and newborn outcomes related to maternal warming during cesarean delivery. J Obstet Gynecol Neonatal Nurs. 2006;35(3):324-31.

19. Panossian C, Simões CM, Milani WRO, Baranauskas MB, Margarido $\mathrm{CB}$. $\mathrm{O}$ uso da manta térmica no intraoperatório de pacientes submetidos à prostatectomia radical está relacionado com a diminuição do tempo de recuperação pósanestésica. Rev Bras Anestesiol. 2008;58(3):220-6.

20. Forbes SS, Eskicioglu C, Nathens AB, Fenech DS, Laflamme $C$, McLean RF, et al. Evidence-based guidelines for prevention of perioperative hypothermia. J Am Coll Surg. 2009;209(4):492-503.

21. Kurz A. Thermal care in the perioperative period. Best Pract Res Clin Anaesthesiol. 2008;22(1):39-62.

22. Burns SM, Wojnakowski M, Piotrowski K, Caraffa G. Unintentional hypothermia: implications for perianesthesia nurses. J Perianesth Nurs. 2009;24(3):167-76.

23. Burger L, Fitzpatrick R. Prevention of inadvertent perioperative hypothermia. Br J Nurs. 2009;18(18):1114, 1116-9. 